\title{
NOTAS SOBRE CORPO, SAÚDE E LUDICIDADE
}

Recebido em: 18/08/2009

Aceito em: 26/11/2009

\section{Maria Isabel Brandão de Souza Mendes ${ }^{1}$ José Pereira de Melo ${ }^{2}$}

Universidade Federal do Rio Grande do Norte Natal - RN - Brasil

RESUMO: Este artigo apresenta uma reflexão teórica que contribuiu com o desenvolvimento da pesquisa intitulada " $\mathrm{Na}$ contramão da disciplinarização dos corpos: as atividades lúdicas, as unidades de saúde da família e a intersetorialidade" financiada pelo Ministério do Esporte - Rede CEDES. O objetivo desse estudo foi estabelecer reflexões sobre discursos e práticas educativas em saúde, tecendo relações com a ludicidade e o corpo. Primeiramente, indaga-se sobre o reforço da ludicidade a disciplinarização dos corpos e depois, sobre a possibilidade de se oferecer resistências a esse processo. Diante dos argumentos apresentados, ressaltou-se a importância de refutarmos uma visão idealizada da ludicidade e a necessidade de compreendermos o lúdico como fenômeno existencial, que pode estar presente em diversos momentos do cotidiano.

PALAVRAS-CHAVE: Corpo Humano. Saúde da Família. Atividades de Lazer.

\section{NOTES ABOUT THE BODY, HEALTH AND PLAYFUL}

ABSTRACT: This article presents a theoretical analysis contributed to the development of research entitled "In the wrong way the of disciplining of bodies: the playful, the units of family health and intersectoral" financed for the Net CEDES of the Ministry of Sport by. The aim of this study was to establish reflections on discourses

\footnotetext{
${ }^{1}$ Doutora em Educação. Professora do Curso de Educação Física da Universidade Federal do Rio Grande do Norte. Pesquisadora da Rede CEDES do Ministério do Esporte e do Grupo Corpo e Cultura de Movimento da UFRN.

${ }^{2}$ Doutor em Educação Física. Professor do Curso de Educação Física e do Programa de Pós-Graduação em Educação da Universidade Federal do Rio Grande do Norte. Pesquisador e líder do Grupo Corpo e Cultura de Movimento da UFRN.
} 
and educational practices in health, build relationships with the playfulness and the body. First, to investigate about the strengthening of playfulness to the disciplining of bodies and then, on the possibility of offering resistance to this process. In front the arguments presented, stressed the importance to refute an idealized view of the playfulness and the need to understand playful as existential phenomenon, which may be present at various times daily.

KEYWORDS: Human Body. Family Health. Leisure Activities.

\section{INTRODUÇÃO}

Este artigo apresenta uma reflexão teórica que contribuiu com o desenvolvimento da pesquisa intitulada "Na contramão da disciplinarização dos corpos: as atividades lúdicas, as unidades de saúde da família e a intersetorialidade" financiada pelo Ministério do Esporte - Rede CEDES. O objetivo desse estudo foi estabelecer reflexões sobre discursos e práticas educativas em saúde, tecendo relações com a ludicidade e o corpo. Primeiramente, indaga-se sobre o reforço da ludicidade a disciplinarização dos corpos e depois, sobre a possibilidade de se oferecer resistências a esse processo.

Cabe destacar, que desde a Antiguidade, diversos discursos e práticas educativas em saúde são construídos e re-significados conforme o tempo e o espaço em que estão inseridos e variam de acordo com a compreensão de corpo e o tipo de educação que se almeja. O desejo de governar o corpo é expresso por meio de diferentes interesses e revelam rupturas e continuidades (MENDES, 2007).

A ideia de governo para Foucault (1997) está relacionada às técnicas e modos de guiar a conduta dos seres humanos. As modernas formas de governabilidade, que surgem a partir do processo de secularização das ações e discursos construídos na pastoral cristã estão associadas a ideia de governo atrelada à obediência incondicional aos preceitos médicos. 
Na pastoral cristã, a idéia de governo refere-se a uma espécie de vigilância sobre si atrelada à obediência incondicional ao mestre, ao exame ininterrupto e a confissão exaustiva (FOUCAULT, 1997).

Desse modo, percebemos que as modernas formas de governabilidade podem ter contribuído para o estabelecimento da relação entre a ludicidade e a saúde, por meio da ideologia do ser saudável.

O projeto de alcançar o ser saudável ideal propagado na sociedade pelos médicos tem como intuito instaurar na vida humana a positividade da saúde e surge a partir do final do século XVIII, como ressalta Foucault (2001), ao fazer referência à medicina européia. Numa sociedade em que a procura pelos prazeres da vida era considerada como provocadora de distúrbios na saúde da população e gerava desigualdades sociais, a tarefa do médico tornava-se política. Seu dever era informar, dominar e coagir a população. A vigilância se tornava freqüente e pulverizada. A consciência médica se generalizava, difundia-se, e cada indivíduo tinha o dever de obter informações sobre os saberes médicos. Para atingir seus objetivos, então, a Medicina moderna não se limitava somente a um conjunto de técnicas da cura e do saber exigidos; abrangia ainda um conhecimento do ser humano saudável, um ser humano modelo, ausente de doença. Com essa postura normativa, não é mais cabível aos médicos unicamente aconselhar sobre a vida em equilíbrio. Estes passam a ter a intenção de regular as relações físicas e morais dos indivíduos e da sociedade.

A partir do final do século XVIII, com a instauração da ideologia do ser saudável o corpo humano é visto de forma fragmentada. O biopoder se instaura e o corpo que vive, suporte do nascimento, da morte, da longevidade e da saúde é controlado para ser inserido no campo produtivo e econômico, servindo, desse modo, 
para o desenvolvimento da sociedade industrial. As estratégias biopolíticas desejam intervir sobre a maneira de viver, para ampliar a vida, controlar os acidentes, o aleatório, as deficiências. O poder sobre a vida se propõe a instaurar uma administração calculista da existência (FOUCAULT, 1988).

É nos fins do século XVIII que emerge a sociedade disciplinar. As disciplinas para Foucault (1999, p.179) "são técnicas para assegurar a ordenação das multiplicidades humanas". Ordem, docilização e utilidade são objetivos a serem alcançados pela sutileza de um poder que é multifacetado. Organizar o espaço, regular o tempo, vigiar o indivíduo e controlar o seu comportamento são estratégias utilizadas para incluí-lo num sistema normalizador.

A sociedade disciplinar que emerge no final do século XVIII, se desenvolve durante o século XIX e de certo modo ainda é a nossa (MUCHAIL, 2004). A disciplina está relacionada a uma maneira de se organizar o espaço no sentido de distribuir os corpos. Refere-se ainda a um modo de obter o controle integral do tempo e tem como recurso principal à vigilância permanente. A disciplina está vinculada ao registro do que é vigiado e exacerba a produção de um padrão de normalidade.

O projeto de alcançar o ser saudável ideal mantém relações com o processo de disciplinarização dos corpos e se espalha por diversas épocas e sociedades, contribuindo com a associação da saúde a modelos ideais de corpo (MENDES, 2007).

O projeto de alcançar o ser saudável ideal contribui com a associação da ludicidade a disciplinarização dos corpos.

\section{O LÚDICO COMO DISPOSITIVO DISCIPLINAR: POSSIBILIDADES DE ENFRENTAMENTOS?}


Como podemos observar no livro de Sant`Anna (1994), na década de 70 do século XX, o domínio do lúdico e a preocupação com a administração dos usos do tempo livre exacerbaram uma série de discursos e práticas que funcionavam como um dispositivo disciplinar.

Em prol da boa forma, o "prazer justificado" associado à saúde e à velocidade era regido por regras que buscavam organizar e ampliar o lazer programado, tendo como modelo os planos de governo dos anos 70. Em tempo de ditadura militar, observou-se a inserção de verdades e de hierarquias dos prazeres no campo lúdico, contribuindo com a classificação dos usos do tempo livre:

Fazer ginástica, usar o tempo livre com atividades físicas e esportivas, cultuar a descontração e um certo tipo de corpo saudável e produtivo, passaram a fazer parte dos padrões de normalidade estabelecidos socialmente (SANT`ANNA, 1994, p. 11).

O lúdico associado a uma compreensão a-histórica e apolítica de lazer era reconhecido como instrumento de correção de condutas e como possibilidade de administrar as expectativas dos usuários. Nesse cenário educativo, observa-se a naturalização do lazer, a associação do lúdico a dimensão terapêutica, deixando-se de investir na gratuidade das diversões e do descanso (SANT`ANNA, 1994).

Outra reflexão importante sobre essa temática é encontrada no livro "O 'mito' da atividade física e saúde" de Yara de Carvalho, quando a autora destaca a reorganização do discurso higienista nas décadas de 70 e 80 do século XX. Yara de Carvalho se remete, dentre outros itens, à Campanha "Mexa-se" da Rede Globo que mobilizava a população para a prática de atividades físicas, "com audiência de cinqüenta milhões de pessoas nos horários principais sob patrocínio comercial (CARVALHO, 1995, p. 58): 
Manter a boa forma, por meio dos exercícios físicos, seja caminhadas ou corridas nesse período, era um ideal a ser perseguido no tempo livre. Em nome de uma saúde perfeita e para compensar as agruras do tempo de trabalho, procurava-se por meio de um lazer programado exaltar o corpo, "exibi-lo com roupas coloridas, colocá-los em atividades lúdicas e descansá-lo" (SANT`ANNA, 1994, p. 85).

Nesse contexto, a exaltação e criação de atividades lúdicas tinham a ambição de tratar os doentes e solucionar os problemas sociais. Além disso, as atividades lúdicas ao terem como foco o culto ao corpo belo, saudável, jovem e ágil, contribuíram com o processo de disciplinarização.

Esse processo de disciplinarização dos corpos também pode ser percebido nos discursos e práticas em saúde que se pautam na busca por um estilo de vida ativo pautado num padrão de corpo magro que emergem no século $\mathrm{XX}$.

Alex Fraga traz reflexões importantes sobre o modelo do estilo de vida ativo ao estudar o Programa Agita São Paulo. O autor apresenta detalhes sobre a "retórica político-sanitária" que contribui com a dissimulação de formas de controle e destaca que:

[...] o estilo de vida ativo está em toda a parte. Multiplica-se em textos científicos, matérias jornalísticas, filmes, novelas, clínicas médicas, academias de ginástica, currículos escolares, peças de marketing (FRAGA, 2006, p.19).

Como podemos perceber no estudo de Fraga (2006), o estilo de vida ativo configura-se como uma forma de controle da sociedade hodierna e opera sobre os corpos por meio de tecnologias de poder. A intenção é exacerbar um modo de conduzir a vida e regular a existência. O que importa são os 30 minutos destinados para a atividade física diária. 
Meia hora por dia para realizar atividades físicas e cultuar a descontração, seja em casa, no trabalho ou no lazer. Os padrões de normalidade estabelecidos destinam-se a combater o sedentarismo e a buscar a magreza corporal.

As atividades físicas são receitadas como medicamento em substituição aos remédios convencionais e reforçam a relação linear entre atividade física e saúde. Preceitos são ditados como benefícios de um estilo de vida ativo e que são recomendados para aqueles que são considerados moralmente decadentes, por não se enquadrarem em comportamentos considerados positivos legitimados pelos saberes médicos (FRAGA et al., 2009).

Nas ruas, em sites da internet, em programas televisivos, em artigos científicos e até mesmo nas conversas informais, somos bombardeados por produtos, modelos e fórmulas que prometem a manutenção da juventude e um corpo perfeito. Nesse contexto, o culto ao corpo se espalha sutilmente por diversos cenários educativos, inclusive no âmbito do lazer.

Conselhos diferenciados, mas que possuem semelhanças, como destaca Gomes (2009), ao analisar o desenvolvimento de propostas midiáticas e acadêmicas para a educação do indivíduo saudável. Sua análise se centrou no suplemento semanal "Equilíbrio" da Folha de São Paulo e nas produções realizadas pelo Núcleo de Pesquisa em Atividade Física \& Saúde da Universidade Federal de Santa Catarina.

$\mathrm{O}$ autor destaca que numa sociedade que tem como parâmetros a velocidade, a agilidade e a mobilidade, promessas de bem estar e felicidade insistem na responsabilidade individual e na mudança de comportamentos, inclusive no âmbito do lazer. Nesse sentido, o lazer ativo é venerado e o lazer passivo é combatido, perpetuando as hierarquias dos prazeres. 
Porém, mesmo com a proliferação de discursos e práticas educativas em saúde que exacerbam formas de controle e favorecem o desabrochar de ações associadas à vida como objeto de governo, necessitamos destacar alguns questionamos:

- Será que em tempo de estilo de vida ativo, as atividades lúdicas somente contribuem com a instauração de padrões de normalidade, com a administração dos usos do tempo livre e funcionam como um dispositivo disciplinar?

- Como as pessoas enfrentam esse processo de vigilância e controle sobre seus corpos nas relações vivenciadas no cotidiano?

Para acirrar o debate, buscamos elementos, que colaboram com a reflexão sobre as relações de poder instauradas sobre o corpo e que estão pulverizadas pela sociedade. Buscamos refletir não somente sobre as possibilidades de aceitação desses modelos, mas também sobre possibilidades de abrir espaços capazes de gerar resistências a esses ditames, pois como revela Foucault (1979), nem o poder é total, nem ocorre de modo unilateral. Um dos pontos relevantes a se ressaltar é que todo discurso gerador de poder, possui no seu interior, um discurso de contra poder.

Desse modo, o caráter relacional do poder nos faz perceber que podem existir brechas, pontos móveis e transitórios nas relações humanas que suscitem lutas, enfrentamentos, possibilidades de resistências a disciplinarização dos corpos.

Para tanto, o corpo humano não pode ser reconhecido somente como objeto de intervenção, mas é necessário também reconhecê-lo como sujeito da existência (NÓBREGA, 2009).

A compreensão fenomenológica de corpo é emblemática para percebermos a plasticidade corpórea. Para Merleau-Ponty (1999a, b), o corpo humano é condição de existência e está atado ao mundo em que vive. O corpo humano possui uma situação 
ambígua, por possuir uma história pessoal e coletiva em constante transformação. Além de ser objeto é sujeito, é visível e invisível, impreciso, polissêmico e inacabado.

O corpo humano é vivo, intersubjetivo, orgânico, histórico, sexuado, capaz de criar, de imaginar, de pensar, de sentir dor e prazer, de trabalhar, de festejar e ficar ocioso, provocar encontros e desencontros, capaz de se comunicar até mesmo pelo que silencia, de atribuir sentido às suas experiências vividas, de construir e reconstruir valores. [...] O corpo humano é totalidade e abertura, um ser bruto em constante metamorfose, situado em relações de poder, capaz de ser dominado e tomar decisões, de ser retificado e de realizar acrobacias (MENDES, 2007, p.126).

Diante da compreensão fenomenológica de corpo, ressaltamos que o lúdico desabrocha das experiências vividas pelos sujeitos no contexto em que está inserido e pode estar relacionada a diversos interesses.

Vivemos numa época em que a sociedade enaltece os pressupostos racionalistas e atribui um valor supremo às atividades produtivas, em detrimento das atividades lúdicas. Para Huizinga (2001), a ludicidade é uma construção cultural que é reconstruída de acordo com cada cenário histórico social.

Além disso, o lúdico não se reduz às brincadeiras das crianças. Pode se manifestar em qualquer manifestação em que haja alegria, divertimento e prazer, mesmo que haja momentos de tensão e conflitos.

Apesar do lúdico comumente ser associado à infância, estimulando preconceitos, a ludicidade pode ser percebida por pessoas com diferentes faixas etárias. A restrição do lúdico à infância está associada à idéia de que as pessoas de outras idades estão preocupadas com coisas sérias, consideradas produtivas e que não se entregam às atividades lúdicas (GOMES, 2004). 
Essa compreensão coloca em oposição o lúdico e a produtividade e o concebe como sendo algo inútil. O pensamento de Gomes (2004) é interessante para pensarmos no lúdico, com vistas a superar uma visão idealizada. O lúdico é concebido como expressão humana de significados culturais relacionado ao brincar, seja consigo, com o outro ou com o entorno. O lúdico é construído culturalmente e está relacionado a condições da existência, como normas políticas e sociais, princípios morais e regras educacionais.

O lúdico pode reforçar estereótipos, desabrochar discriminações e consumismo, ou então, incitar a contestação e resistência aos ditames espalhados pela sociedade. Para a autora, "o lúdico representa uma oportunidade de (re) organizar a vivência e (re) elaborar valores, os quais se comprometem com determinado projeto de sociedade" (GOMES, 2004, p. 146).

O lúdico, desse modo, pode contribuir com a disciplinarização dos corpos, ao suscitar a adequação às padronizações, ou então, exacerbar formas de resistências aos modelos instituídos na contemporaneidade.

\section{TECENDO CONSIDERAÇÕES}

Após estabelecermos algumas reflexões sobre discursos e práticas educativas em saúde, tecendo relações com a ludicidade e o corpo, ressaltamos a compreensão da necessidade de refutarmos uma visão idealizada da ludicidade. Ressaltamos ainda, a relevância de colaborarmos com a construção de discursos e práticas educativas em saúde que superem uma postura normativa guiada por modelos determinísticos fundamentados na ideologia do ser saudável. Discursos e práticas 
educativas em saúde que se contraponham aos poderes biopolíticos e não hierarquizem os prazeres.

Compreendemos, então, que para caminharmos na contramão da disciplinarização dos corpos, as atividades lúdicas também podem ser vislumbradas como possibilidade de abrir espaço para a atenção ao corpo e os cuidados com a saúde e ao mesmo tempo permitir uma ligação à ação humana pública e coletiva, sem se pautar na busca por um padrão ideal de corpo e de saúde.

Portanto, ao compreendermos o lúdico como fenômeno existencial, que pode estar presente em diversos momentos do cotidiano, seja em situações individuais ou em relações sociais, desejamos que essas reflexões possam colaborar com estudos que relacionam as temáticas da saúde e do lazer. Pois, como destaca Carvalho (2003), estudos que caminham nessa direção, ainda são escassos, apesar de serem considerados temas atuais e relevantes para a população.

Sugerimos, então, que sejam oferecidas manifestações culturais que despertem ludicidade em diferentes cenários educativos e que contemplem uma diversidade de corpos de diferentes comunidades, sem se ter à preocupação com a busca de um corpo ideal.

Desejamos que as pessoas tenham oportunidades de expressar suas histórias pessoais e coletivas e mesmo estando imersos numa sociedade que exacerba discursos e práticas que reforçam o desejo de controle sobre a vida, possam construir diferentes significados ao participarem de momentos lúdicos. 


\section{REFERÊNCIAS}

CARVALHO, Y. M. O mito da atividade física e saúde. São Paulo: Hucitec, 1995.

. Formação profissional em políticas públicas de lazer com enfoque na saúde. IN: MARCELLINO, N. C. (Org.). Formação e desenvolvimento de pessoal em lazer e esporte. São Paulo: Papirus, 2003.

FOUCAULT, M. História da sexualidade 1: a vontade de saber. Tradução de Maria Thereza da Costa Albuquerque e J. Guilhon Albuquerque. Rio de Janeiro: Graal, 1988.

Resumo dos cursos do Collége de France (1970-1982). Tradução de Andréa Daher. Rio De Janeiro: Jorge Zahar, 1997.

. Vigiar e punir: nascimento da prisão. Tradução de Raquel Ramalhete. 21. ed. Petrópolis: Vozes, 1999.

$\frac{1}{1979 .}$. Microfísica do poder. Tradução de Roberto Machado. Rio de Janeiro: Graal,

O nascimento da clínica. Tradução de Roberto Machado. 5. ed. Rio de Janeiro: Forense Universitária, 2001.

FRAGA, A. B. Exercício da informação: governo dos corpos no mercado da vida ativa. São Paulo: Autores Associados, 2006.

FRAGA, A. B. et al., "Sedentarismo é...": concepções de praticantes de caminhada e medicalização das práticas corporais. In: FRAGA, A. B.; MAZO, J. Z.; STIGGER, M. P. (Org.). Políticas de lazer e saúde em espaços urbanos. Porto Alegre: Gênese, 2009. p. 21-35.

GOMES, C. L. Lúdico. In: (Org.). Dicionário crítico do lazer. Belo Horizonte: Autêntica, 2004. p. 141-146.

GOMES, I. M. Conselheiros modernos: propostas para a educação do indivíduo saudável. Brasília: Thesaurus/CBCE, 2009.

HUIZINGA, J. Homo ludens: O jogo como elemento da cultura. 5. Ed. São Paulo: Perspectiva, 2001.

MENDES, M.I.B.S. Mens Sana in Corpore Sano: saberes e práticas educativas sobre corpo e saúde. Porto Alegre: Sulina, 2007.

MERLEAU-PONTY, M. Fenomenologia da Percepção. 2. ed. São Paulo: Martins Fontes, 1999a.

MERLEAU-PONTY, M. O visível e o invisível. 3. ed. Tradução de José Artur Gianotti e Armando Moura d Oliveira. São Paulo: Perspectiva, 1999 b.

MUCHAIL, S. T. Foucault, simplesmente: textos reunidos. São Paulo: Loyola, 2004. 
NÓBREGA, T. P. Corporeidade e educação física: do corpo objeto ao corpo sujeito. 3. ed. Natal: Editora da UFRN, 2009.

SANT`ANNA, D. B. O prazer justificado: história e lazer. São Paulo: Marco Zero, 1994.

\section{Endereço dos Autores:}

Maria Isabel Brandão de Souza Mendes

Rua das Algas 2190 - Ponta Negra

Rio Grande do Norte - Natal

Cep: 59.090-410

Endereço Eletrônico: isabelmendes@ufrnet.br

José Pereira de Melo

Universidade Federal do Rio Grande do Norte (UFRN)

Departamento de Educação Física/UFRN

Campus Universitário, SN, Lagoa Nova Natal - RN

CEP: 59072-970

Endereço Eletrônico: melo@digi.com.br 